\title{
WCSC 2018: the 8th world chess software championship
}

Article

Accepted Version

Krabbenbos, J., van den Herik, J. and Haworth, G. (2019) WCSC 2018: the 8th world chess software championship. ICGA Journal, 40 (3). pp. 194-206. ISSN 1389-6911 doi: https://doi.org/10.3233/ICG-190079 Available at https://centaur.reading.ac.uk/78437/

It is advisable to refer to the publisher's version if you intend to cite from the work. See Guidance on citing.

To link to this article DOI: http://dx.doi.org/10.3233/ICG-190079

Publisher: IOS Press

All outputs in CentAUR are protected by Intellectual Property Rights law, including copyright law. Copyright and IPR is retained by the creators or other copyright holders. Terms and conditions for use of this material are defined in the End User Agreement.

\section{www.reading.ac.uk/centaur}

\section{CentAUR}

Central Archive at the University of Reading

Reading's research outputs online 


\section{WCSC 2018: The $8^{\text {th }}$ World Chess Software Championship}

Jan Krabbenbos, Jaap van den Herik and Guy Haworth ${ }^{1}$

Amersfoort, the Netherlands, Leiden, the Netherlands and Reading, UK

The ICGA's 8th World Chess Software Championship was held at the Stockholmsmässan in Stockholm, Sweden on July $14^{\text {th }}-15^{\text {th }}$, the day after the Speed Chess 'opener' and before the 'open platform' World Computer Chess Championship (Krabbenbos et al., 2018a/b). At the same time, the venue also hosted the international conferences IJCAI, ECAI, AAMAS, ICML, ICCBR and SoCS. The main sponsor was Digital Game Technology, DGT.

The common platform here was a Dell laptop with i7-8550U, $1.80 \mathrm{GHz}$ processor running on MS Windows 10 x64 with 16 GByte of internal memory. Nine engines took part, see Table 1 and CPW (2018), and so there were nine rounds, this year at a tempo of $45^{\prime}+15^{\prime \prime} /$ move. This tournament was played with commentary by International Grand Master Harry Schussler. We had many spectators owing to the fact that the conference hall hosted the set of conferences mentioned above.

Table 1

The participants in WCSC 2018 (CPW, 2018)

\begin{tabular}{cccccc}
\hline$\#$ & id & Program & Author(s) & Country & Operator \\
\hline $\mathbf{1}$ & B & BOOOT & Alex Morozov & UA & A M \\
$\mathbf{2}$ & H & HIARCS & Mark Uniacke & GB & Harvey \\
$\mathbf{3}$ & C & CHIRON & Ubaldo Andrea Farina & IT & U A F \\
$\mathbf{4}$ & G & GINKGO & Frank Schneider & DE & Kai Himstedt, \\
$\mathbf{5}$ & J & JONNY & Johannes Zwanzger & DE & Timo Haupt \\
$\mathbf{6}$ & K & KOMODO & Don Dailey, Mark Lefler \& Larry Kaufman & US & Erdogan Günes \\
$\mathbf{7}$ & P & PAULINE & Patrick Corey & US & P C \\
$\mathbf{8}$ & S & SHREDDER & Stefan Meyer-Kahlen & DE & S M-K \\
$\mathbf{9}$ & T & THE BARON & Richard Pijl & NL & R P \\
\hline
\end{tabular}

Round 1: JONNY - BOOOT 1/2-1/2, HIARCS - KOMODO 1/2-1/2, CHIRON - THE BARON 1-0, SHREDDER GINKGO $1 / 2-1 / 2$, PAULINE bye

The first round did not have any spectacular outcomes although JONNY and KOMODO may have expected a bit more from their game. For JONNY, the first twenty moves were from its opening book. Thereafter White proved to have some aggressive ideas in mind but BOOOT was able to annihilate all potential threats and reach a rook endgame in which Black had slightly the upper hand. Nevertheless, the draw was never out of sight. Indeed, 'draw' was JONNY's prediction on move 63 and this result was agreed on move 66. We remark that BоOOT did play this game without access to an endgame database.

\footnotetext{
${ }^{1}$ Corresponding author: g.haworth@ reading.ac.uk
} 
The game HIARCS - KOMODO was one between two giants. From the well-known Caro-Kann, the sharpest opening variation was chosen by Black. White was well prepared but could not get any advantage. During the game KOMODO collected some small benefits and hoped that the totality of these would lead to a tangible advantage. However, the trials that Black essayed did not result in real progress. This implied that the spectators for a long time saw forward and backward play. During this stage, White was prepared for a black penetration and prevented any dangerous situation. Finally, the opponents agreed to a draw.

The game CHIRON - THE BARON started with the Dutch opening, the Leningrad variation. It is known as a fighting variant. The openings phase was followed by a series of subtle midgame manoeuvers in which White managed with 22. Ne4 to block the black e-pawn and gain some positional advantage. Soon thereafter, the white bishop appeared on the scene and after 25. Be6, see Fig. 1a, it was clear that White had some advantage.

Black countered inventively but White managed to keep the advantage. It won the pawn on e5 and thereafter, the technical phase though difficult was not really an obstacle for CHIRON. On move 43, THE BARON resigned.

The former world champion program SHREDDER had some high hopes for a good result in this very strong tournament. It is remarkable to see how strong the programs are and without any doubt, we may state that seven to eight programs here play above human world championship level. This implies that they are able to envisage the plans of the opponent. In many games, we therefore see anticipating moves intended to prevent any danger for the program's position. Opponent GINKGO is no exception to this rule. Here it is noted that GINKGO is different from GRIDGINKGO since GINKGO was forced to use the uniform platform. If the players were human then the game might have been exciting but here, the opponents understood each other's movements, exchanged the pieces in time, took strategic positions and reached a natural draw in the end.

Standings after R1: 1 CHIRON 1/1; 2-7 BOOOT, HIARCS, GINKGO, JONNY, KOMODO, SHREDDER 1/2/1; 8 PAULINE 0/0; THE BARON 0/1
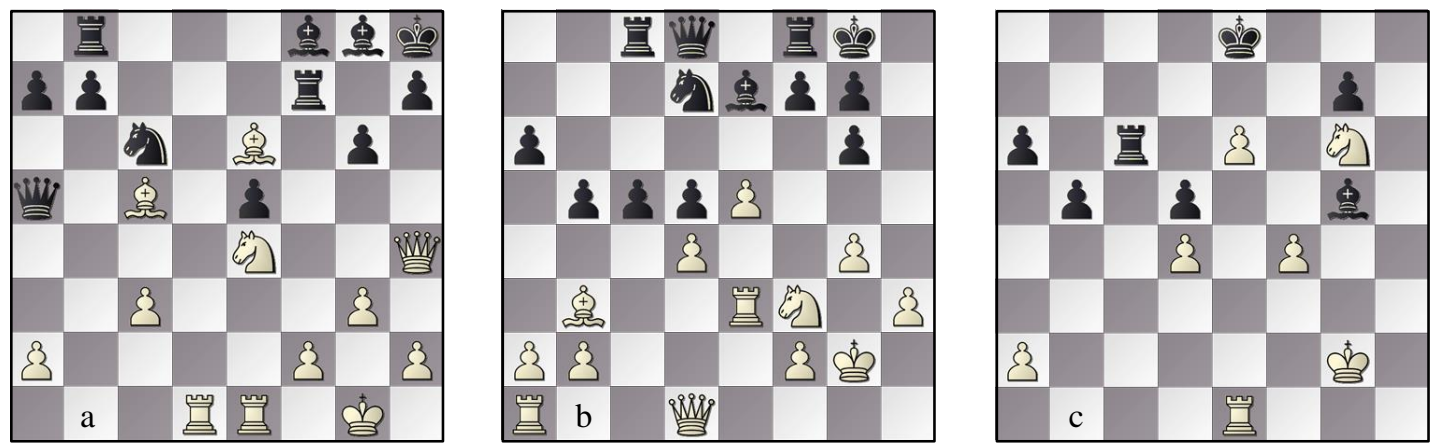

Fig. 1. (a) R1, Chiron - THe BARON 25b; R2, BOOOT - HiarCs (b) $21 \mathrm{~b}$ and (c) $39 \mathrm{~b}$.

Round 2: THE BARON - SHREDDER 1/2-1/2, KOMODO - CHIRON 1/2-1/2, BOOOT - HIARCS 1-0, PAULINE - JONNY 0-1, GINKGO bye

In this round, we saw the first appearance of the program PAULINE, a newcomer in our community. The programmer is Patrick Corey. He named his program after his mother who is 86 and is in bad health. The name giving showed the touching courtesy of a son towards his mother. As we all know 
it is very difficult for newcomers to find their way in the strong community we have today with our top programmers. Although PAULINE managed to get opponent JONNY out of book as soon as the first move, it did not show much resistance towards the former world champion program. The game was a walkover for JONNY.

In the game BOOOT - HIARCS the good old Ruy Lopez was played. Both sides followed well-known variations and well-known manoeuvers. On move 21, Black made a decision, which was wrong although the move looks logical, see Fig. $1 \mathrm{~b}$.

Black played 21.... c4 but should have played 21 ... cxd4: the majority on the queenside was not a real asset. The white attack on the kingside was more dangerous. The attack was not directly against the black king but was meant to obtain spatial advantage and free play for White's pieces. In fact, these are more modern concepts than the tactical concepts which we used in previous games. White emphasized its possibilities by playing $\mathbf{2 7 .}$ h5 anticipating $27 . \ldots$ gxh5 28. Bf5 Nf8 29. Bxc8 Rxc8 30. gxh5. Although Black attempted to solve the problems on the queenside by playing 30 ... c3 it was too late. White neutralized the dangers on that side and built up an advantage in the center and the kingside. In particular the move 39. $\mathbf{4} 4$ as in Fig. 1c established the fact that White was in the lead. Some moves later, Black resigned.

In the game THE BARON - SHREDDER, White used the advantage of the first move by playing solidly and without taking any risk. The game went from opening play to midgame play in an equal situation. Anybody who expected that the formal world champion would outplay THE BARON in that phase was wrong. THE BARON played well and was ever alert. It did not give SHREDDER any chance for a counter-attack. In the end, they arrived at an equal position and agreed the draw.

KOMODO - CHIRON was a game between two equally strong opponents. KOMODO started with a Queen Pawn opening whereas Black developed in a natural way. However, in the position which resulted from this special opening play, there was no direct point to focus on. This implied that both sides were looking for possibilities to strengthen their position. That was easier said than done. As the game continued, Black tried to increase its power in the center by playing $24 . . .8$ Bc5 as in Fig. 2a but White quietly responded with $\mathbf{2 7}$. $\mathbf{~ b 3}$ forcing Black to retract the bishop. Thereafter White did not see any better opportunity than withdrawing its knight and Black started to repeat moves. After another repetition, a draw was agreed.
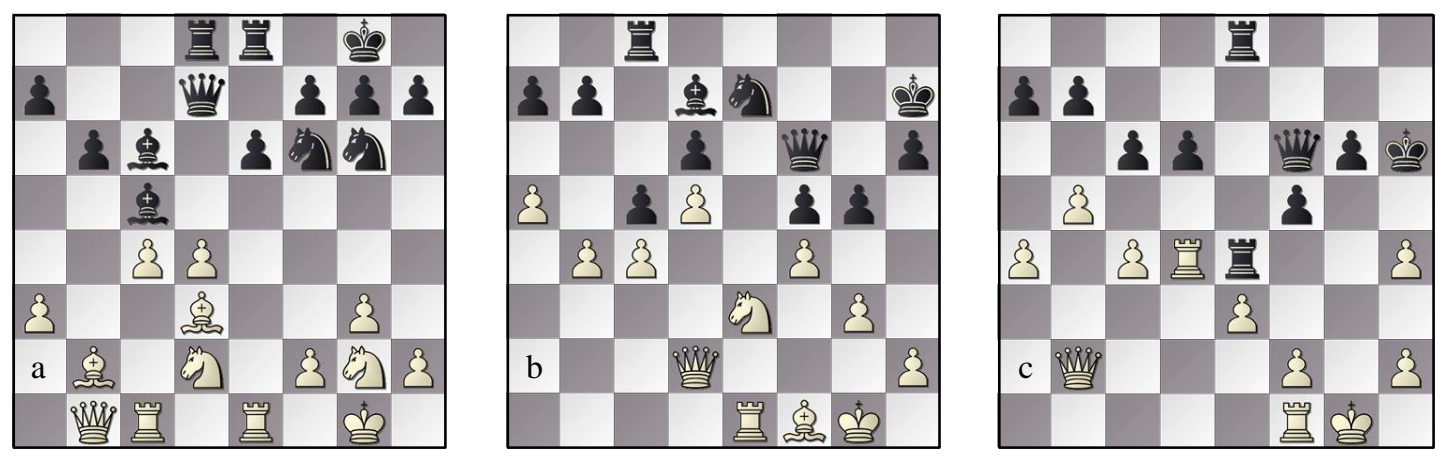

Fig. 2. (a) R2, KomOdo - ChIRON 25w; R3 (b) GinKGO - THE BARON 31 w and (c) SHREDDER - Komodo 30w.

Standings after R2: 1-3 BOOOT, CHIRON, JONNY 11/2/2; 4-5 KOMODO, SHREDDER 1/2; 6 GINKGO 1/2/1; 7-8 HIARCS, THE BARON $1 \frac{1}{2} / 2$; 9 PAULINE 0/1 
Round 3: HIARCS - PAULINE 1-0, CHIRON - BOOOT 1/2-1/2, SHREDDER - KOMODO 1/2-1/2, GINKGO THE BARON 1-0, JONNY bye

The game HIARCS - PAULINE looked like a game between a giant and a dwarf. The opening read as follows 1. b3 g6 2. Bb2 e5 3. Bxe5 f6 and White was already a pawn up. The remainder of the game was played without much inspiration and White won, mating on move 26.

The game GINKGO - THE BARON started as an irregular opening which transformed into a Philidor variation. White obtained the usual advantage and collected small benefits that improved its position. Still Black was not without counter play. However, White played very well and with $\mathbf{3 1}$. Rb1 as in Fig. $2 b$ it was able to emphasize its advantage. Black played courageously with 31. ... gxf4 32. Ng2 fxg3 33. bxc5 (opening the b-file) gxh2+ 34. Kh1 Rc7. White must have analysed this line more deeply since the continuation of play showed that it was right in its decision to play $\mathbf{3 2}$. Ng2. In the sequel of the moves played, Black was unable to take on c5 (37... Qxc5 38. Rb5) and therefore had to play 37. ... Rd7. The remainder of the game was in GINKGO's good hands which forced THE BARON to resign after move 50 .

The game SHREDDER - KOMODO was a real fight. KOMODO defended with the Dutch defense, Leningrad variation. At the beginning, one started to believe that a draw was unavoidable since many pieces were exchanged and the position seemed to be balanced. However, White decided to accept Black's invitation and exchanged its queen for two rooks, see Fig. 2c, by playing 30 Rxe4 Qxb2 31 Rxe8. In a difficult position with pawns on both sides, it was difficult to assess who was better off in the materially unbalanced position. Was the queen stronger by its mobility or were the two rooks a strong combination of forces that could outperform the queen? For human beings it is difficult to evaluate and difficult to play such a game. Apparently, the computers were able to compute long lines of sequences of moves and at the end of each line they found a draw. Logically, after 58 moves, a draw was agreed.

The game CHIRON - BoOOT was an exciting fight. This was not seen from the opening which developed quietly. Nevertheless, in the midgame, White showed its attempt to win by playing 26. bxa5 as in Fig. 3a. White was not only a pawn up but had calculated that its pieces were in the right place to catch the counter attack by Black. Play continued 26. ... Rb8 27. Nb5 Nc5 28. Nfd4 Rec8.
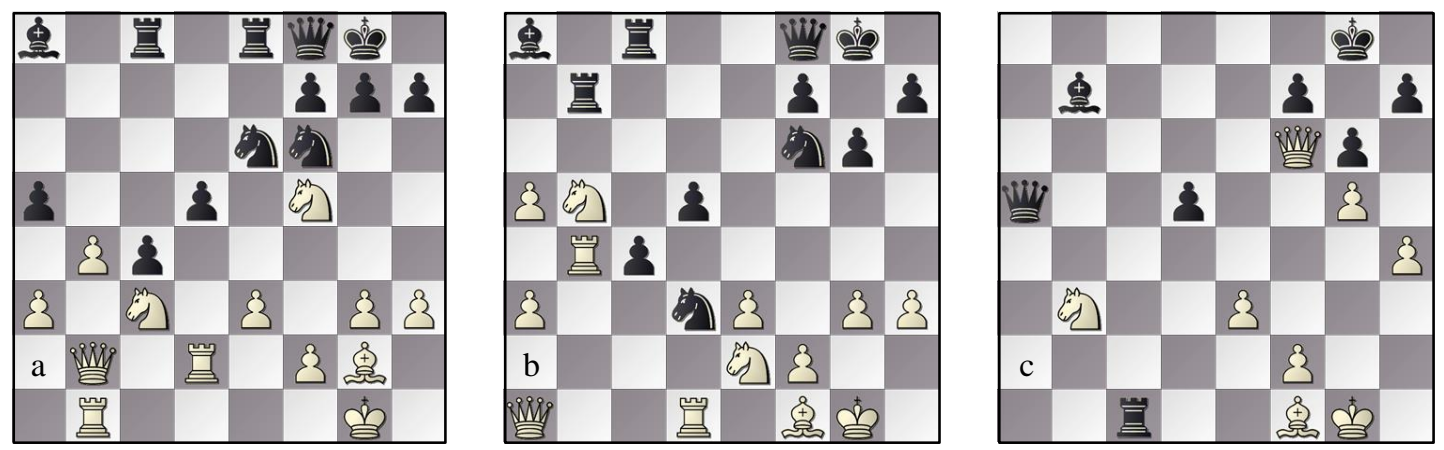

Fig. 3. R3, Chiron - BOOOT (a) 26w, (b) 34w and (c) 44b.

The black position is strong since the square $\mathrm{d} 3$ is under its control: the pawn on a5 is worthless. However, this is easier said than brought into practice. At move 33 Black believed that its chances 
were now ripe for exploration. Booot played 33.... Nd3, see Fig. 3b, 34. Qxf6 Nxb4 35. Ned4 Na2 36. Ra1 Rxb5 37. Nxb5 c3 38. Rxa2 c2 39. Rxc2 Rxc2.

Now it is difficult to attribute advantage to either side. Play continued as follows 40. g4 Rc1 41. g5 Bb7 42. Nd4 Qxa3 43. h4 Qxa5 44. Nb3, see Fig. 3c. The moves that followed are forced and lead to a draw: 44. ... Rxf1 45. Kxf1 Qb5+ 46. Kg1 Qxb3 47. Qd8+, the end of a fascinating game.

Standings after R3: 1-2 BOOOT, CHIRON 2/3; 3-4 GINKGO, JONNY 11/2/2; 5-7 HiarCs, KomOdo,

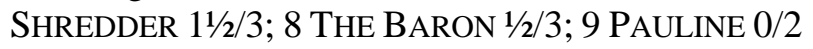

Round 4: KOMODO - GINKGO 1/2-1/2, BOOOT - SHREDDER 1/2-1/2, PAULINE - CHIRON 0-1, JONNY HIARCS $1 / 2-1 / 2$, THE BARON bye

Apparently, the program PAULINE is the weakest of all participants. This may lead to nice combinations because its opponents can show their strength. That happened in this round again and the winner was CHIRON. Even in the opening, it contemplated a king attack by playing 5.... h5. All went as anticipated and the game was the first one to finish in the round.

In the game JONNY - HIARCS, the opening book turned out to be of essential importance. HIARCS had a weak move in its opening library which showed up on move four: it is the combination of 3.... b6 and 4. ... c5 with no pawn on d5. As the game progressed, Black was limited in space and mobility of pieces. Dark clouds were in the air and the prospects for HIARCS were worse. Still it was difficult for JONNY to find a way to a measurable advantage. JONNY believed that with move 28. e5, see Fig. 4a, White could keep its advantage after 28 . ... dxe5 with 29. f5.

The complications thereafter looked good. Time and again, White had small threats and many times, Black had only one move. However, one move is enough, particularly if it is a good move. In the game it looked like JONNY was playing in such way that it was often forcing HIARCS to the only good move. If you take the moves played as the best moves played for White, then the strategy led to a draw. This draw was a clear and well-deserved success for HIARCS which defended excellently.

KOMODO - GINKGO was a fight between two contenders for the first place. KOMODO showed a new idea from the opening. In a double king fianchetto it combined 11. h4 and 12. h5 gxh5 with the manoeuver 9. Re1, 13. Re4, 14. Rh4. To avoid too much pressure on its position, Black started to eliminate some attackers by exchanging them. Still, White kept the pressure on, see Fig. 4b.

Having pressure is not sufficient in itself because the idea is to increase the pressure so that the opponent collapses. Put another way, increasing pressure is only a stepping-stone towards winning the game. In this case, White could not find any stepping stone and this implied that Black recovered and was ready to take over the initiative. The white rook on $\mathrm{h} 4$ was forced to retreat with $\mathbf{2 3}$. Rhh1 and later, Black found an opportunity to push the h-pawn with 33.... h4. This progress set the board on fire as Black penetrated the white position with 34. ... Rxf2. Deep analysis of the game would determine the game theoretical value at this point. Nevertheless, as matters went White found a way out and after some ingenious moves, the game ended in a draw before the board witnessed perpetual check.

The game BOOOT - SHREDDER had an attractive start as the opening book had included the sacrificial capture 11. ... Bxh2+, see Fig. 4c. For inexperienced players, this would seem a surprise but in fact it was all theory and was estimated to result in a game of equal chances. Apparently, both programs were afraid that the equal chances were difficult to handle and therefore they helped the theoretical evaluators by playing consolidating moves. With that approach, the tension of the position illustrated 
in Fig. 4c disappeared. The game hove into positional waters and the strength of the players on both sides of the board guaranteed a drawn outcome.

Standings after R4: 1 CHIRON 3/4; 2 BOOOT 21/2/4; 3-4 GINKGO, JONNY 2/3; 5-7 HIARCS, KomOdO, SHREDDER $2 / 4 ; 8$ THE BARON $1 / 2 / 3 ; 9$ PAULINE $0 / 3$
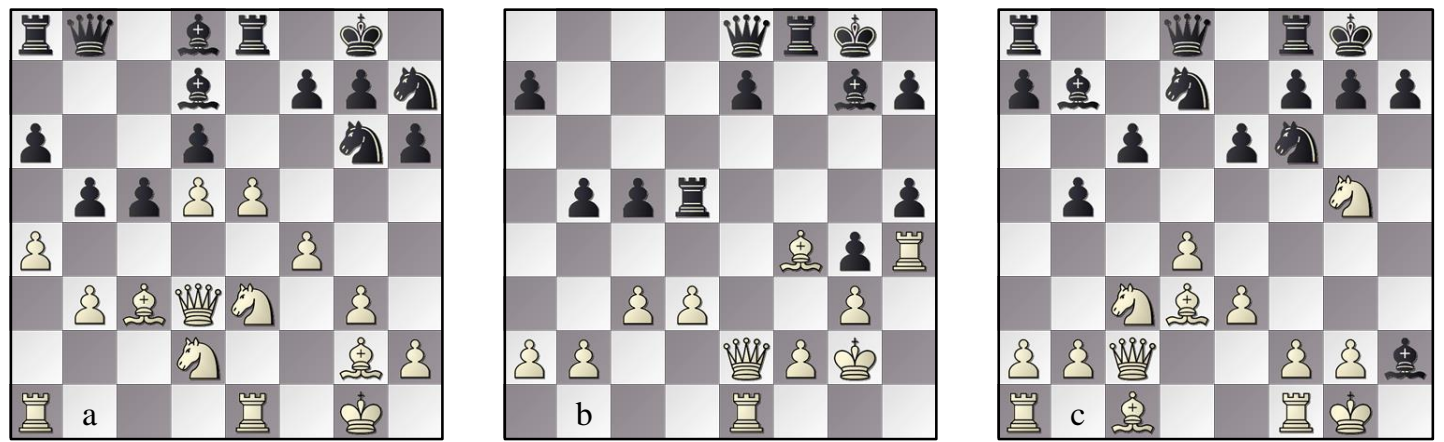

Fig. 4. R4: (a) JoNNY - HiARCS 28b, (b) Komodo-GinkGo 23w and (c) BOOOT - SHREDDER 12w.

Round 5: CHIRON - JONNY 0-1, SHREDDER - PAUline 1-0, GinKGO - BOOOT 1/2-1/2, THE BARON KOMODO 0-1, HIARCS bye

SHREDDER had a walk over in its short game with PAULINE. It is an easy sentence to write but it makes the standings of our tournament difficult to interpret. Anyway, for the spectator it is interesting to see how a super-class program crushes a rather weak program.

Chess programmers have the power to influence the opening play of their programs directly since they implement the opening theory. For the middlegame, this is more difficult as then the programmers are depending on the evaluation functions of their programs. Richard Pijl, the programmer of THE BARON, was facing the above reality in person. THE BARON played 19. b3 which was a horrible move, see Fig. 5a.

In particular, with White's castling on the queenside and the positioning of his white bishop, Black was immediately in a position to take over the initiative and, as it turned out, this was in KOMODO's good hands. A few strong moves were sufficient to overpower THE BARON. The win for KOMODO was a firm step towards first place.

Leader CHIRON had JONNY in this round as its opponent. JONNY is a former world champion and CHIRON a well-designed runner-up. In such games, precise tuning and deep knowledge of the dynamics of the game are important. CHIRON was aiming for spatial advantage on the queenside. JONNY focused on a kingside attack and on threats on the white king. JONNY's ambitions were clear from the beginning. People from the CHIRON camp later admitted that the program knows the value of pawn structures very well but not in relation to the context on the board. JONNY did not know this weakness but nevertheless, exploited it in a wonderful way. As in Fig. 5b, Black has just played 16. ... h4.

After 17. gxh4, the move $17 \ldots \mathrm{Nh} 2$ is excellent. After $17 \mathrm{Nxh} 4$, there follows 17 .. Rxh4. Of course, CHIRON saw that both of these moves were impossible to play: the program believed it still had time for its action on the queenside and played 17. bxc6. Undeterred, Black continued with its plan by playing 17.... hxg3. After 18. hxg4 fxg4 19. fxg3 gxf3 20. Bxf3 bxc6, Black had full play and many 
chances against the white king whereas White was empty-handed. Black completed its work in the next 20 moves: a well-deserved win by JONNY.

The game GINKGO - Booot had a Russian flavour but with a stamp that is seldom seen in this opening. Nevertheless, it was a game with fresh and refreshing ideas such as an indirect exchange of queens, no care for double pawns and pawn structures, and preference given to the dynamics of the rooks. Both programs gave similar values to the structures and characteristics mentioned above. So, from the beginning, the evaluation was equal and that remained so up to the end of the game, a welldeserved draw for both sides.

Standings after R5: 1 JONNY 3/4; 2-5 BOOOT, CHIRON, KOMODO, SHREDDER 3/5; 6 GINKGO 21/2/4; 7 HIARCS $2 / 4 ; 8$ THE BARON $1 / 2 / 4 ; 9$ PAULINE 0/4
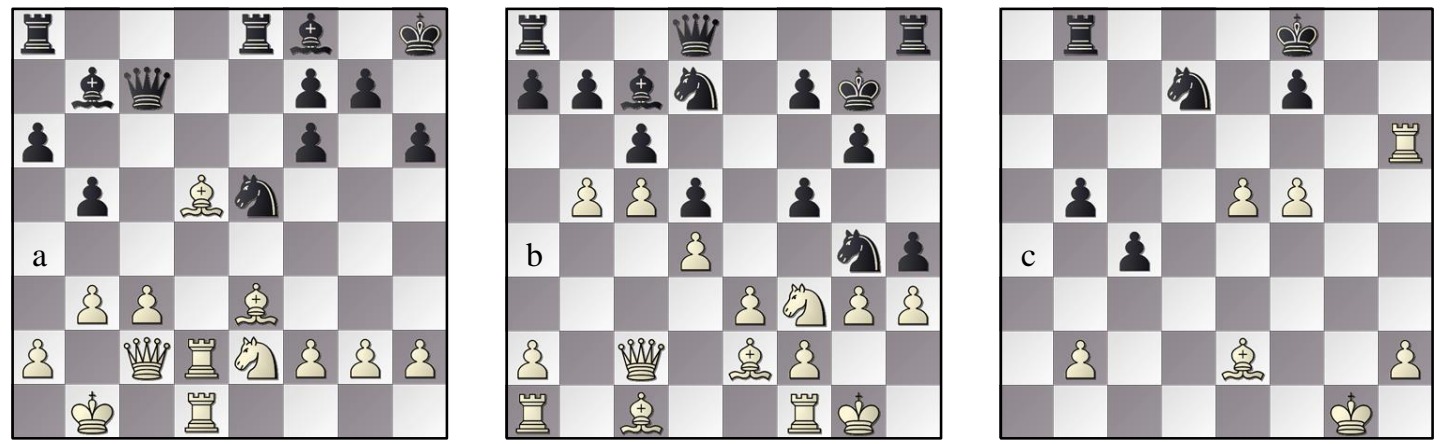

Fig. 5. R5: (a) THE BARON - KOMOdo 19b, (b) CHIRON - JONNY 17w; (c) R6, HiARCS - CHIRON 31w.

\section{Round 6: BOOOT - THE BARON 1-0, PAULINE - GINKGO 0-1, JONNY - SHREDDER 1/2-1/2, HiarCS -} CHIRON $1 / 2-1 / 2$, KOMODO bye

Every round in this tournament starts with a small crowd around the board of PAULINE. Strong programs show their combinatorial capacities for public and opponent: the public can enjoy the fireworks and the opponent can learn from them. Chess programmers have taken seventy years to reach the status of playing stronger than humans. Therefore, it is much appreciated when newcomers also aim to achieve this programming excellence. In this round, PAULINE lost to GINKGO.

Probably THE BARON is the weakest of all programs here that have super-grandmaster strength. But among such programs, there is a strict hierarchy and that is based on their mutual results. THE BARON is a very good player but we see that it is handicapped when it plays Black against a strong opponent. Round six was no exception. We see THE BARON playing well up to a certain point and then we see that it is overpowered by its opponent. There is no weak point to analyze. It is more a matter of the consistent strength of the opponents. The current programs in this WCSC are very strong and BOOOT showed its strength to THE BARON. In the middlegame, BOOOT took the initiative, limited the playing space of the black pieces and outmanoeuvred THE BARON so that an opening was made to penetrate into the black position. The end was played convincingly by ВоOОT.

HIARCS and CHIRON are two programs that came well prepared to Stockholm. Their opening preparations might not be perfect but they are at least very good. In their game, they were able to show these preparations. Up to move 30, they followed known games, see Fig. 5c. The example games provide us with three possibilities, being $31 \mathrm{Rh} 8,31 \mathrm{Rh} 5$ and $31 \mathrm{Rh} 3$ : HIARCS played a new move, namely 31. e6. So far, six games had been played from the position of Fig. 5c, two for each 
variation: all had ended in a draw. In the game HIARCS - CHIRON, the outcome was the same but it was certainly reached in an attractive and inventive way.

The number of games that have been played between SHREDDER and JONNY in their head-to-head competition is considerable. The players themselves have the precise scores partitioned into years, colours and places. Here we see a draw to add to the many already in their lists. The game is certainly interesting but from a spectator point of view, there are no surprising twists or other remarkable moves to mention. The game started as a Semi-Slav, followed theory and sorted out the difficulties in the middlegame well. All in all, a draw was agreed with mutual approval.

Standings after R6: 1 BoOot 4/6; 2-3 GINKGO, JONNY 31/2/5; 4-5 CHIRON, SHREDDER 31/2/6; 6 KOMODO $3 / 5 ; 7$ HIARCS $2 \frac{1}{2} / 5 ; 8$ THE BARON $1 \frac{1}{2} / 5 ; 9$ PAULINE 0/5

Round 7: SHREDDER - HIARCS 1/2-1/2, GINKGO - JONNY 1/2-1/2, THE BARON - PAULINE 1-0, KOMODO - BOOOT $1 \frac{1}{2}-1 / 2$, CHIRON bye

The game THE BARON - PAULINE was important for the final standings in the tournament but also for the public in the tournament hall. They enjoyed the game very much. The tournament commentator IGM Harry Schussler was among them. He encouraged the players to continue their fight up to the very end because he wanted to show the final position to the public, see Fig. 6a. They were happy with his gesture.

The tournament is in its final phase but there are still two rounds to go after this one. Having a top position is important. Such ideas may nowadays be incorporated in the programs by setting the contempt factor. Future developments will help the programmers and will lead to autonomously setting the contempt factor. Whatever the case we will follow this development closely but at this moment we must establish that the programs are playing in the same range of playing strength. SHREDDER and HIARCS did their utmost: admittedly, HIARCS took a few more risks and showed more initiatives. According to both evaluation functions, the programs believed that HIARCS had a small advantage. SHREDDER was not impressed, defended adequately and never gave HIARCS a real chance to materialize the dynamic advantage that Black might have had. When White played 69. b5 the advantage disappeared and in consequence, the game duly ended in a draw. The result was welldeserved by both sides.

The game GINKGO - JONNY was important since both programs also had to play in the last rounds. Both programs were fighting for their last chance to reach a high position in the final standings. A decisive outcome of their contest would help the winner. However, they turned out to be of equal strength, at least in this contest. Analysing the game would probably confirm the idea that both programs have equal playing strength. In the current game White managed to keep the opening advantage, keeping almost the whole game alive. However, the advantage was small and in the endgame, the draw was never far away. On move 57, they agreed to a draw by move repetition.

KOMODO - BOOOT played a very peaceful game. They opened in a French way but not with the help of a sharp variation. Players and spectators saw pieces drop next to the board always with the same value. The remaining power on the board was therefore also in balance. The same observation applies to the dynamic possibilities on the board. It was all friendly exchanges of pieces up to the moment that the last pawn disappeared from the board. A draw was agreed.

Standing after R7: 1 BOOOT 41/2/7; 2-3 GINKGO, JONNY 4/6; 4 SHREDDER 4/7; 5-6 CHIRON, KOMODO 31/2/6; 7 HIARCS 3/6; 8 THE BARON 11/2/6; 9 PAULINE 0/6 

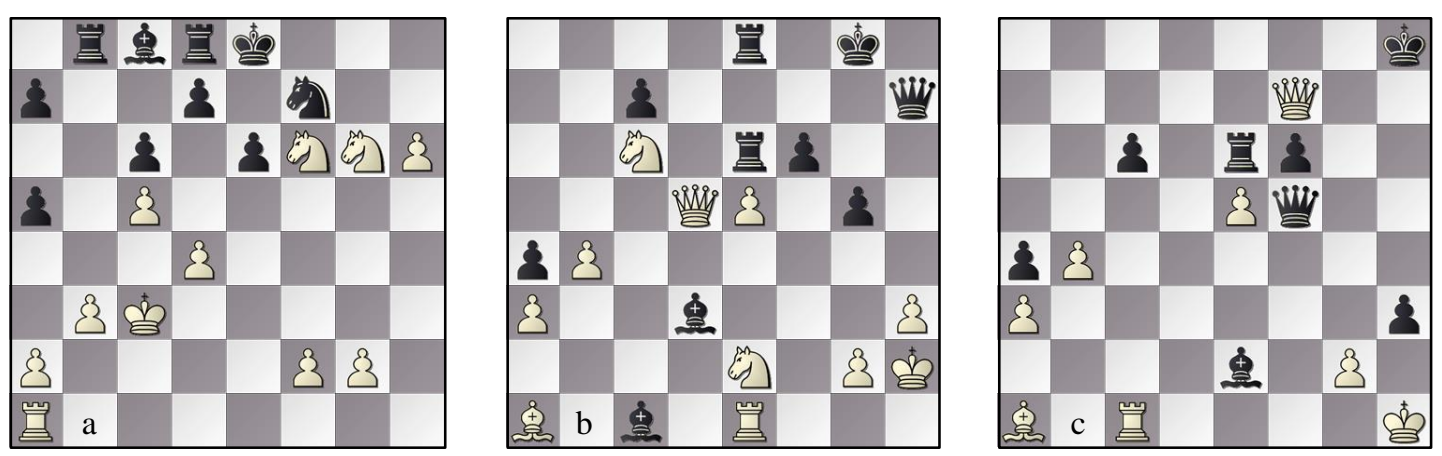

Fig. 6. (a) R7, The BARON - PAuline 26b; R8, Hiarcs - Ginkgo (b) $39 \mathrm{~b}$ and (c) 50w.

\section{Round 8: PAULINE - KOMODO 0-1, JONNY - THE BARON 1-0, HIARCS - GINKGO 1/2-1/2, CHIRON - SHREDDER $1 / 2-1 / 2$, BOOOT bye}

PAULINE played against KOMODO. Both programmers had the same expectations of the outcome. Even so, they were still curious as to how the programs would play to arrive at this result. The moves played by PAULINE were remarkable since there were more side moves than center moves. These had no impact on KOMODO's play. The program mobilized its forces, penetrated the white position and captured many pieces before ending by mating the white king.

JONNY was facing THE BARON which was playing as Black again. For a long time, the game was tight and from an objective point of view, equal. Yet JONNY tried to complicate the position so that THE BARON could commit an error. This strategy was not easy since THE BARON played well and cleaned the board file by file. It looked a good strategy but JONNY was able to lead THE BARON down the wrong track. Once this had succeeded, JONNY completed the task in a technical way with precise play. With this victory, JONNY remained in the running for the championship.

HIARCS - GINKGO was an exciting game. Both programs felt the pressure to win in order to maintain a chance to win the world title. Both programs had already proven their playing strength. This meant that the current encounter would show us a spectacle of power and ingenuity. At the start, HIARCS seemed to have the initiative but in fact, that advantage went up and down. It is not clear whether the theoretical value of the game had been changed during the course of the game. But it is clear that on move 39, see Fig. 6b, the position was complex and difficult to evaluate.

In the events that followed many things happened but apparently the value of the game remained in the same range. Still it is difficult to weigh material advantage against the dynamics of the game such as giving perpetual check. Fig. $6 \mathrm{c}$ shows the final position in which both players agreed a draw.

The game CHIRON - SHREDDER looked like a game played between two opponents who know each other's style very well. Both programs played fast and tried to limit the opportunities of the opponent as much as possible. Still it is difficult to identify deep subtleties in clear positions without any tension. As the game went, see Fig. 9, there were no problems for either side and in the final position they repeated moves.

From the standings below, we saw that only four programs were candidates for the WCSC title. Moreover, one particular set of results would have placed three of the candidates in a play-off: JONNY drawing, BOOOT and GINKGO winning. So, the ninth round was keenly anticipated. 
Standings after Round 8: 1 JonNy 5/7; 2-4 BOOOT, GINKGO, KOMODO 41/2/7; 5 SHREDDER 41/2/8; 6 CHIRON 4/7; 7 Hiarcs 31/2/7; 8 THE BARON 11/2/7; 9 PAULINE 0/7

Round 9: GINKGO - CHIRON 1/2-1/2, THE BARON - HIARCS 1-0, KOMODO - JONNY 1-0, BOOOT PAULINE 1-0, SHREDDER bye
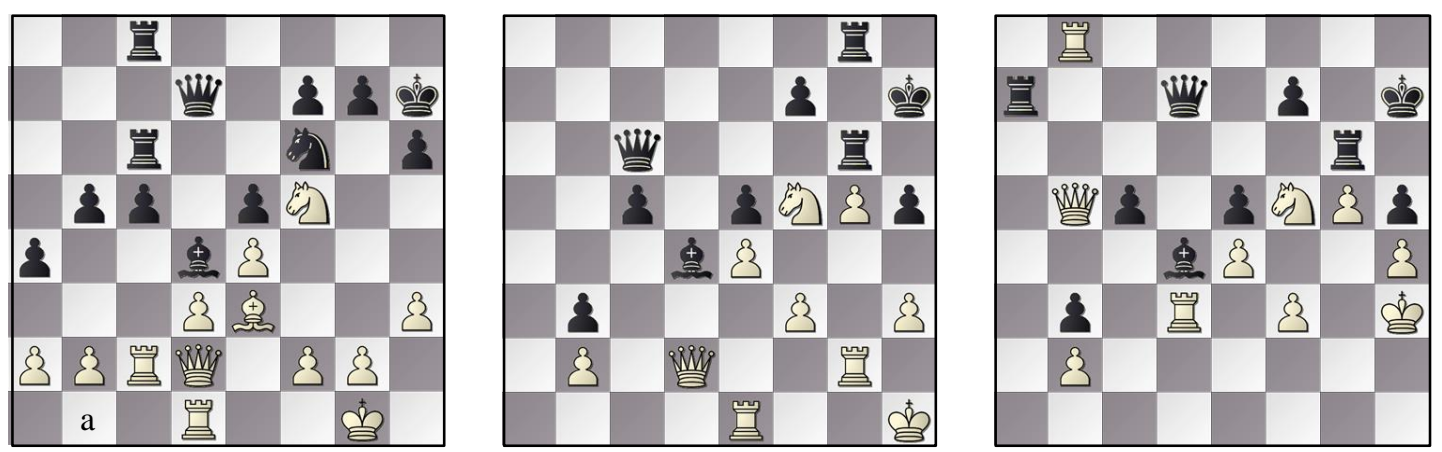

Fig. 7. R9, KOMODO - JONNY (a) 25w, (b) $51 \mathrm{~b}$ and (c) $68 \mathrm{w}$.
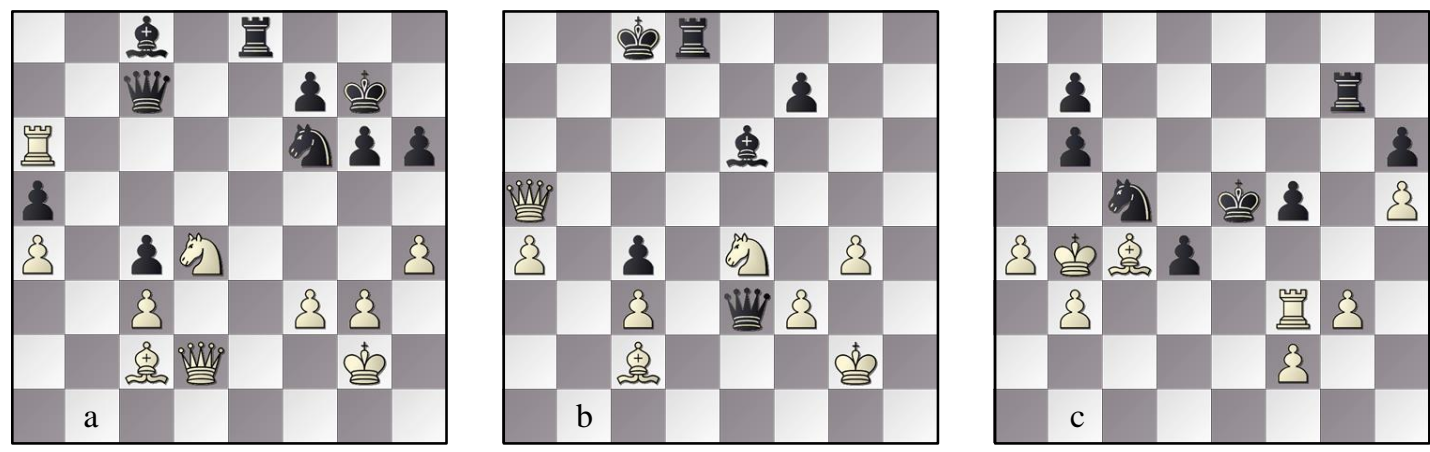

Fig. 8. R9, GINKGO - CHIRON (a) 58w and (b) 70b and (c) BARON-HiARCS 56w.

The game BOOOT - PAULINE was the first game to come to a decision. BOOOT had an easy game, was able to win in 17 moves and ended its tournament as the leader in the clubhouse with $5 \frac{1}{2}$ points.

The game KOMODO - JONNY was important for KOMODO since it was its last chance to remain a candidate for the title. For JONNY it was even more so as winning the game would mean that JONNY would be the WCSC champion 2018. The audience was excited to see this spectacular game being played in Stockholm. The game started with a very quiet Giuco Piano. It was so 'piano' that there is actually not much to mention. Still KOMODO was preparing its trick in the position of Fig. 7a. For the experienced chess player, the threat is clear, namely $\mathbf{2 5}$. Bxh6 which was indeed played. Black had an answer with 25. ... Nxe4 giving the rook on c6 the task of protecting the square h6. After 26. dxe4 gxh6 play continued with 27 . Qe2 b4.

Materially the game was still in balance but the knight on $\mathrm{f} 5$ is clearly stronger than the bishop on $\mathrm{d} 4$. To put it even more strongly, the knight on $\mathrm{f} 5$ is stronger than one of the rooks. This is exemplified in Fig. 7b, a position that occurred after 51. Re1. Between move 27 and move 50 many manoeuvers 
were completed but in essence, the position did not alter in structure. During this phase, subtleties, techniques and knowledge about weak and strong positions had the highest priority.

From Fig. 7b, the game continued for another 17 moves to arrive at the position of Fig. 7c. Here the path to the win is easy: exchange queens and take the pawn on b3.The result was that JONNY lost both its lead and its title aspirations, and KOMODO was tied with BOOOT on $5 \frac{1}{2} 2$ points.

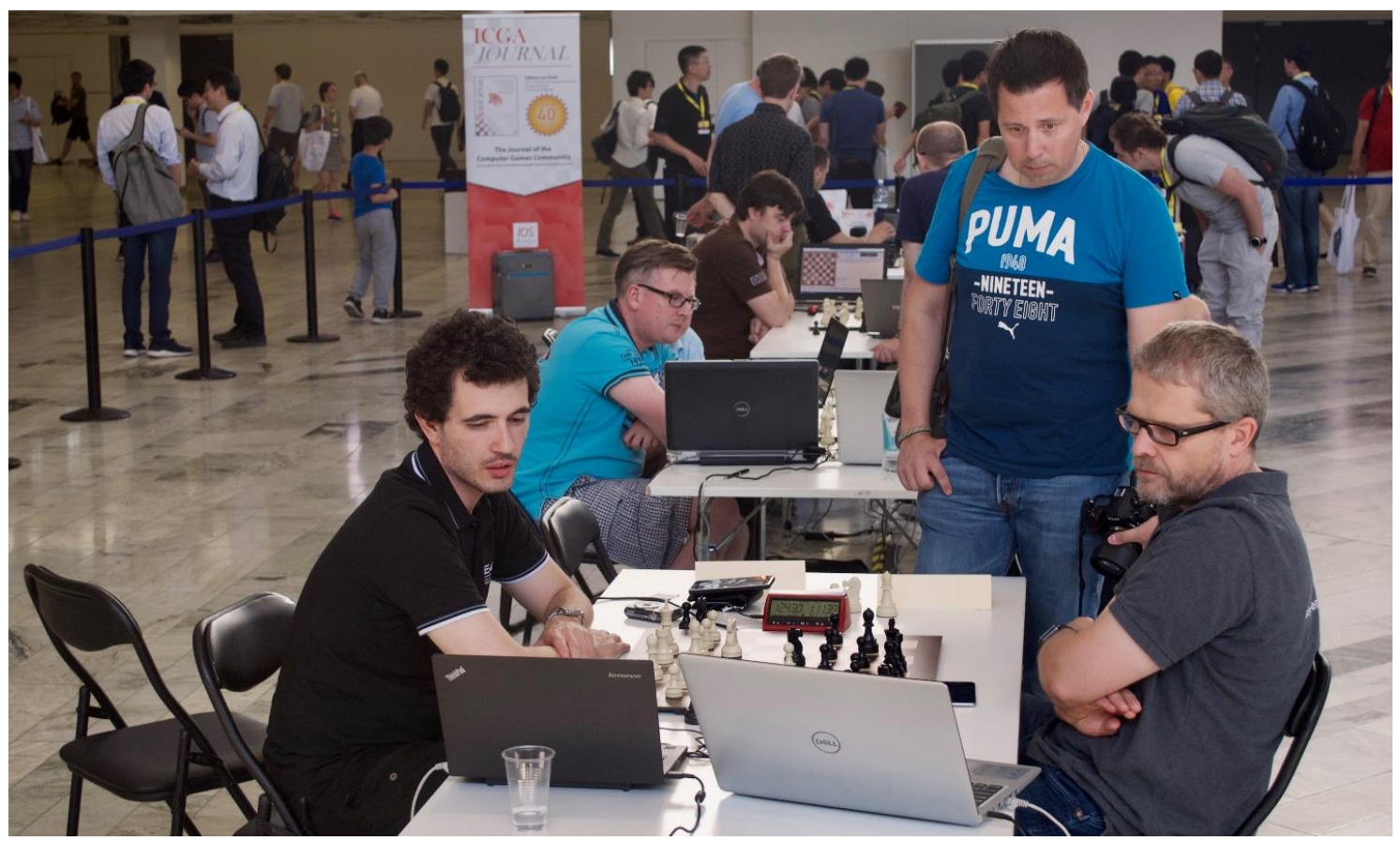

Fig. 9. Game 8.1/29: CHIRON-SHREDDER, Andrea Ubaldo and Stefan Meyer-Kahlen, 'SSDF' Lars Sandin looking on.

The game GINKGO - CHIRON was also a Giuco Piano. Here the course was more in line with the theoretical variations. For a long time, the balance was not broken by either side. For GINKGO it was important to win the game therefore - we assume - the program was prepared to take any risk that was reasonable and explainable. Such a position occurred as in Fig. 8a. By playing 58. Rxf6, White managed to revive winning chances and tension. The game contained 58... Kxf6 59. Qxh6 Qe5 60. g4 Bd7 61. Qh7 Qd6 62. h5 gxh5 63. Qh6+ Ke7 64. Qxh5.

In this double-edged position, White was fighting for a win whereas Black was not without chances. After a tough fight, the game finally ended in a draw since Black forced White to give perpetual check by sacrificing the exchange on move 70.... Rd2+, see Fig. 8b. The final moves were 71. Nxd2 Qxd2+ 72. Kg3 Qxc2 73. Qc5+ Kb7 74. Qb5+ Ka8 75. Qa6+ Kb8 76. Qb6+ Ka8 77. Qc6+ Ka7 78. Qc7+ Ka6 79. Qc6+ Ka7 80. Qc7+ Ka6 81. Qc6+ Ka7. GINKGO missed the tie for first by half a point.

In the game THE BARON - HIARCS, we see that THE BARON played convincingly stronger with the White pieces than with the Black pieces. This observation is given for the chess player who follows the moves played by THE BARON one by one. The win over HIARCS was a great performance which we celebrate with Fig. $8 \mathrm{c}$ in which the final winning plan on the queenside is revealed. 
Standings after Round 9: 1-2 BOOOT, KOMODO 51ำ; 3-4 GINKGO, JONNY 5; 5-6 CHIRON, SHREDDER $41 \frac{1}{2} ; 7$ HIARCS $31 \frac{1}{2} ; 8$ THE BARON 21/2; 9 PAULINE 0

Table 2

The WCSC 2018 cross-table

\begin{tabular}{|c|c|c|c|c|c|c|c|c|c|c|c|c|c|c|c|}
\hline id & Program & $\mathbf{K}$ & B & $\mathbf{G}$ & $\mathbf{J}$ & $\mathbf{S}$ & $\mathrm{C}$ & $\mathbf{H}$ & $\mathbf{T}$ & $\mathbf{P}$ & $\mathbf{W}$ & D & \multicolumn{3}{|c|}{ L Score S-Bgr } \\
\hline $\bar{K}$ & KOMODO & & $1 / 2$ & $1 / 2$ & 1 & $1 / 2$ & $1 / 2$ & $1 / 2$ & 1 & 1 & 3 & 5 & 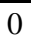 & $51 / 2$ & 19 \\
\hline B & BOOOT & $1 / 2$ & & $1 / 2$ & $1 / 2$ & $1 / 2$ & $1 / 2$ & 1 & 1 & 1 & 3 & 5 & 0 & $51 / 2$ & $18^{1 / 4}$ \\
\hline $\mathrm{G}$ & GINKGO & $1 / 2$ & $1 / 2$ & & $1 / 2$ & $1 / 2$ & $1 / 2$ & $1 / 2$ & 1 & 1 & 2 & 6 & 0 & 5 & $16^{3} / 4$ \\
\hline $\mathbf{J}$ & JONNY & 0 & $1 / 2$ & $1 / 2$ & & $1 / 2$ & 1 & $1 / 2$ & 1 & 1 & 3 & 4 & 1 & 5 & $16^{1 / 4}$ \\
\hline $\mathrm{S}$ & SHREDDER & $1 / 2$ & $1 / 2$ & $1 / 2$ & $1 / 2$ & & $1 / 2$ & $1 / 2$ & $1 / 2$ & 1 & 1 & 7 & 0 & $41 / 2$ & $15^{3} / 4$ \\
\hline $\mathrm{C}$ & CHIRON & $1 / 2$ & $1 / 2$ & $1 / 2$ & 0 & $1 / 2$ & & $1 / 2$ & 1 & 1 & 2 & 5 & 1 & $41 / 2$ & $14^{1 / 2}$ \\
\hline $\mathrm{H}$ & HIARCS & $1 / 2$ & 0 & $1 / 2$ & $1 / 2$ & $1 / 2$ & $1 / 2$ & & 0 & 1 & 1 & 5 & 2 & $31 / 2$ & $12^{1 / 4}$ \\
\hline $\mathrm{T}$ & THE BARON & 0 & 0 & 0 & 0 & $1 / 2$ & 0 & 1 & & 1 & 2 & 1 & 5 & $2^{1 / 2}$ & $53 / 4$ \\
\hline $\mathrm{P}$ & PAULINE & 0 & 0 & 0 & 0 & 0 & 0 & 0 & 0 & & 0 & 0 & 8 & 0 & 0 \\
\hline
\end{tabular}

The play-off.
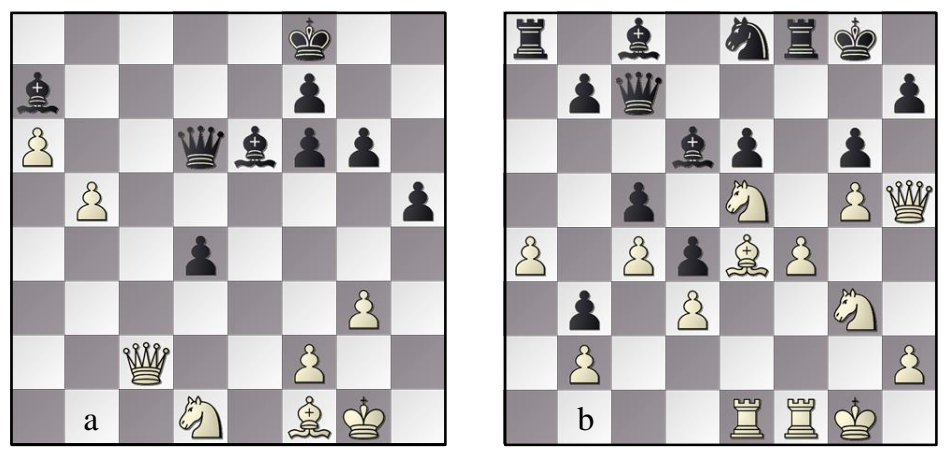

Fig. 10. Play off: (a) Bооот - Комодо 46b and (b) KомоDо - Вооот 28w.

After the Round Robin of nine rounds, the 8th WCSC was not decided even if the three-way tie had not transpired. KOMODO and BOOOT both had $5 \frac{1}{2}$ points and so a play-off between them was necessary. This was organised as three matches of two games followed by an Armageddon, the first decisive match determining the winner. The following matches were scheduled:

Matches $1(2,3)$ : each program had $20^{\prime}\left(10^{\prime}, 5^{\prime}\right)+15^{\prime \prime} /$ move

Armageddon: coin-toss determined colours, White $3^{\prime}+5^{\prime \prime} / \mathrm{m}$, Black $6^{\prime}+10^{\prime \prime} / \mathrm{m}$, the draw being considered a win for Black.

In the event, KOMODO won both games of the first match, and we provide one important snapshot from each game in Fig. 10. In the first game, KOMODO played 46. ... h4, see Fig. 10a. This opened the diagonal b8-h2 and enabled Black to win the game with a mating attack.

After smart play in the opening phase, KOMODO was able to win the second game by a sacrifice which is obvious in Fig. 10b, namely 28. Nxg6 hxg6 29. Bxg6 Bxf4 30. Bxe8. After five more moves, Black resigned. 
The ICGA congratulates the KOMODO team wholeheartedly on winning the WCSC 2018 title. Congratulations also to runner-up BOOOT, the recipient of a copy of CHESSBASE14 donated by Chessbase, and to GINKGO which took third by only half a point ahead of JONNY in Sonneborn-Berger terms. The games, with some annotation, are available for replay from a pgn file (Krabbenbos et al., 2018c) and further analysis will be well repaid.

Table 3

The WCSC 2018 results, round by round

\begin{tabular}{|c|c|c|c|c|c|c|c|c|c|c|c|c|}
\hline \# & id & Program & r1 & $\mathbf{r 2}$ & r3 & r4 & r5 & r6 & r7 & r8 & r9 & Score \\
\hline$\overline{1}$ & $\mathrm{~K}$ & KOMODO & $\mathrm{Hb}^{1 / 2}$ & $\mathrm{Cw}^{1} \frac{1}{2}$ & $\mathrm{Sb}^{1 / 2}$ & $\mathrm{Gw}^{1 / 2}$ & $\mathrm{~Tb} 1$ & & $\mathrm{Bw}^{1 / 2}$ & $\mathrm{~Pb} 1$ & Jw1 & $51 / 2$ \\
\hline 2 & B & BOOOT & $\mathrm{Jb}^{1 / 2}$ & Hw1 & $\mathrm{Cb}^{1 / 2}$ & $\mathrm{Sw}^{1 / 2}$ & $\mathrm{~Gb}^{1 / 2}$ & Tw1 & $\mathrm{Kb}^{1 / 2}$ & & Pw1 & $51 / 2$ \\
\hline 3 & G & GINKGO & $\mathrm{Sb}^{1} / 2$ & & Tw1 & $\mathrm{Kb}^{1 / 2}$ & $\mathrm{Bw}^{1 / 2}$ & $\mathrm{~Pb} 1$ & $\mathrm{JW}_{\mathrm{W}}^{1 / 2}$ & $\mathrm{Hb}^{1 / 2}$ & $\mathrm{Cw}^{1 / 2}$ & 5 \\
\hline 4 & $\mathrm{~J}$ & JONNY & $\mathrm{Bw}^{1 / 2}$ & $\mathrm{~Pb} 1$ & & $\mathrm{Hw}^{1 / 2}$ & Cb1 & $\mathrm{Sw}^{1 / 2}$ & $\mathrm{~Gb}^{1 / 2}$ & Tw1 & $\mathrm{Kb} 0$ & 5 \\
\hline 5 & $S$ & SHREDDER & $\mathrm{Gw}^{1 / 2}$ & $\mathrm{~Tb} b^{1 / 2}$ & $\mathrm{Kw}^{1 / 2}$ & $\mathrm{Bb}^{1 / 2}$ & Pw1 & $\mathrm{Jb}^{1 / 2}$ & $\mathrm{Hw}^{1 / 2}$ & $\mathrm{Cb}^{1 / 2}$ & & $4 \frac{1}{2}$ \\
\hline 6 & $\mathrm{C}$ & CHIRON & Tw1 & $\mathrm{Kb}^{1 / 2}$ & $\mathrm{Bw}^{1 / 2}$ & $\mathrm{~Pb} 1$ & Jw0 & $\mathrm{Hb}^{1 / 2}$ & & $\mathrm{Sw}^{1 / 2}$ & $\mathrm{~Gb}^{1 / 2}$ & $4 \frac{1}{2}$ \\
\hline 7 & $\mathrm{H}$ & HIARCS & $\mathrm{Kw}^{1 / 2}$ & Bb0 & Pw1 & $\mathrm{Jb}^{1 / 2}$ & & $\mathrm{Cw}^{1 / 2}$ & $\mathrm{Sb}^{1 / 2}$ & $\mathrm{Gw}^{1 / 2}$ & Tb0 & $31 / 2$ \\
\hline 8 & $\mathrm{~T}$ & THE BARON & $\mathrm{Cb} 0$ & $\mathrm{Sw}^{1 / 2}$ & $\mathrm{~Gb} 0$ & & Kw0 & $\mathrm{Bb} 0$ & Pw1 & $\mathrm{Jb} 0$ & Hw1 & $2^{1 / 2}$ \\
\hline 9 & $\mathrm{P}$ & PAULINE & & Jw0 & $\mathrm{Hb} 0$ & Cw0 & $\mathrm{Sb0}$ & Gw0 & $\mathrm{Tb} 0$ & Kw0 & $\mathrm{Bb} 0$ & 0 \\
\hline
\end{tabular}

Table 4

WCSC 2018 progress, round by round

\begin{tabular}{|c|c|c|c|c|c|c|c|c|c|c|}
\hline Program & r1 & $\mathbf{r 2}$ & r3 & $\mathrm{r4}$ & r5 & r6 & r7 & r8 & r9 & Score \\
\hline KOMODO & $1 / 2$ & 1 & $1 \frac{1}{2}$ & 2 & 3 & & $31 / 2$ & $41 / 2$ & $51 / 2$ & $51 / 2$ \\
\hline BOOOT & $1 / 2$ & $1 \frac{1}{2}$ & 2 & $2^{1 / 2}$ & 3 & 4 & $4 \frac{1}{2}$ & & $51 / 2$ & $51 / 2$ \\
\hline GINKGO & $1 / 2$ & & $1 \frac{1 / 2}{2}$ & 2 & $2^{1 / 2}$ & $31 / 2$ & 4 & $41 / 2$ & 5 & 5 \\
\hline JONNY & $1 / 2$ & $1 \frac{1}{2}$ & & 2 & 3 & $31 / 2$ & 4 & 5 & 5 & 5 \\
\hline SHREDDER & $1 / 2$ & 1 & $1 \frac{1}{2}$ & 2 & 3 & $31 / 2$ & 4 & $41 / 2$ & & $41 / 2$ \\
\hline CHIRON & 1 & $1 \frac{1}{2}$ & 2 & 3 & 3 & $31 / 2$ & & 4 & $41 / 2$ & $41 / 2$ \\
\hline HIARCS & $1 / 2$ & $1 / 2$ & $1 \frac{1}{2}$ & 2 & & $2^{1 / 2}$ & 3 & $31 / 2$ & $31 / 2$ & $31 / 2$ \\
\hline THE BARON & 0 & $1 / 2$ & $1 / 2$ & & $1 / 2$ & $1 / 2$ & $1 \frac{1}{2}$ & $1 \frac{1}{2}$ & $2 \frac{1}{2}$ & $2^{1 / 2}$ \\
\hline PAULINE & & 0 & 0 & 0 & 0 & 0 & 0 & 0 & 0 & 0 \\
\hline
\end{tabular}

\section{REFERENCES}

CPW (2018). https://tinyurl.com/icga046. Biographies of programs, authors and operators.

Krabbenbos, J., van den Herik, H.J. and Haworth, G.Mㄷ. (2018a). WSCC 2018: the 2018 World Speed Computer Chess Championship. http://centaur.reading.ac.uk/78438/. ICGA Journal, 40(3), \$\$\$. doi:\$\$.

Krabbenbos, J., van den Herik, H.J. and Haworth, G.McC. (2018b). WCCC 2018: the $24^{\text {th }}$ World Computer Chess Championship. http://centaur.reading.ac.uk/78436/. ICGA Journal, 40(3), \$\$-\$\$. doi:\$\$.

Krabbenbos, J., van den Herik, H.J. and Haworth, G.McC. (2018c). This note with an annotated pgn file, available from http://centaur.reading.ac.uk/78437/. 